\title{
Elevated Calcium after Acute Ischemic Stroke: Association with a Poor Short-Term Outcome and Long-Term Mortality
}

\author{
Jong-Won Chung, ${ }^{a}$ Wi-Sun Ryu, ${ }^{b}$ Beom Joon Kim, ${ }^{c}$ Byung-Woo Yoon ${ }^{d}$ \\ a Department of Neurology and the CRCS, Seoul National University Hospital, Seoul, Korea \\ bepartment of Neurology, Dongguk University Ilsan Hospital, Goyang, Korea \\ 'Department of Neurology, Cerebrovascular Center, Seoul National University Bundang Hospital, Seongnam, Korea \\ ${ }^{\mathrm{d}}$ Department of Neurology and the CRCS, Seoul National University Hospital, and Neuroscience Research Institute, College of Medicine, Seoul National \\ University, Seoul, Korea
}

Background and Purpose An elevated intracellular calcium level is known to be a major initiator and activator of ischemic cell death pathway; however, in recent studies, elevated serum calcium levels have been associated with better clinical outcomes and smaller cerebral infarct volumes. The pathophysiological role played by calcium in ischemic stroke is largely unknown.

Methods Acute stroke patients from a prospective stroke registry, consecutively admitted during October 2002-September 2008, were included. Significant associations between the modified Rankin scale distribution at discharge and serum calcium or albumin-corrected calcium were identified using ordinal logistic regression analysis. Cox proportional hazard models were used for survival analysis.

Results Mean serum calcium and albumin-corrected calcium levels of the 1,915 participants on admission were $8.97 \pm 0.58 \mathrm{mg} / \mathrm{dL}$ and $9.07 \pm 0.49 \mathrm{mg} / \mathrm{dL}$, respectively. Second [adjusted odds ratio 1.32 (95\% confidence interval 1.07-1.61)] and third [1.24 (1.01-1.53)] tertiles of serum calcium level and the third [1.24 (1.01-1.53)] tertile of albumin-corrected calcium level were found to be independent risk factors for a poor discharge outcome. Significant relationships were observed with serum calcium [1.19 (1.03-1.38)] and albumin-corrected calcium [1.21(1.01-1.44)] as linear variables. However, only albumin-corrected calcium was associated with long-term mortality, third tertile [adjusted hazard ratio 1.40 (1.071.83)], and increase by $1 \mathrm{mg} / \mathrm{dL}$ [1.46 (1.16-1.84)].

Conclusions Elevated albumin-corrected serum calcium levels are associated with a poorer short-term outcome and greater risk of long-term mortality after acute ischemic stroke.
Correspondence: Byung-Woo Yoon Department of Neurology, Seoul National University Hospital 101 Daehak-ro, Jongno-gu, Seoul 110-744, Korea Tel: +82-2-2072-2875 Fax: +82-2-3673-1990

E-mail: bwyoon@snu.ac.kr

Received: August 19, 2014

Revised: September 10, 2014

Accepted: September 11, 2014

This work was supported by a grant the Korea Healthcare technology RED Project, Ministry of Health and Welfare, Republic of Korea (HI10C2020).

The authors have no financial conflicts of interest.

Keywords Cerebral infarction; Calcium; Patient outcome assessment

\section{Introduction}

The calcium ion $\left(\mathrm{Ca}^{2+}\right)$ is a ubiquitous intracellular messenger during and immediately after an ischemic period, and it influences the cascade of events that lead to subsequent neuronal injury. ${ }^{1}$ Under ischemic conditions, release of glutamate from the neurons and glia activates the $\mathrm{N}$-methyl-D-aspartate (NMDA) receptor and triggers the rapid translocation of $\mathrm{Ca}^{2+}$ from extracellular to intracellular spaces in cerebral tissues. ${ }^{2,3}$ Experimental results indicate that $\mathrm{Ca}^{2+}$ can have a harmful effect on neurons 
under acute ischemic conditions.

The harmful effects of $\mathrm{Ca}^{2+}$ have been studied in regard to its relationship with prevention of neuronal injury in acute ischemia. One small-scale study showed a significant reduction in mortality and neurological impairment after the administration of nimodipine (a calcium antagonist). ${ }^{4}$ Furthermore, collective results suggest that early therapy with oral nimodipine favorably influences the course of acute ischemic stroke. ${ }^{5}$

In contrast to a previously held belief, ${ }^{6,7}$ recent studies suggest that elevated serum calcium levels within 24 hours of stroke onset are associated with smaller infarction volumes and better clinical outcomes after hospital discharge. ${ }^{8,9}$ Interestingly, Appel et al. reported that serum calcium levels at both extremes are associated with greater mortality, and noted optimal long-term survival for a distinct range of serum calcium levels. ${ }^{10}$

In this study, based on the physiologic character of $\mathrm{Ca}^{2+}$ in ischemic conditions, we hypothesized that elevated levels of serum calcium and albumin-corrected calcium may be associated with a poor outcome after stroke in terms of neurologic severity at discharge and mortality.

\section{Methods}

\section{Study population}

Acute stroke patients admitted to Seoul National University Hospital between October 2002 and September 2008 within 7 days of symptom onset were identified from a prospective stroke registry database, and analyzed for this study. The information collected from each patient included stroke subtype as classified by the Trial of Org 10172 in Acute Stroke Treatment (TOAST) criteria, ${ }^{11}$ the National Institutes of Health Stroke Scale (NIHSS) score at the time of admission, thrombolytic treatment during the hyperacute period, and the modified Rankin Scale (mRS) score at discharge (the latter was used as a measure of early functional outcome after stroke). The institutional review board approved the study despite the absence of patient consent due to its retrospective nature and minimal risk to participants [IRB No. H-1011-004-337].

\section{Demographic characteristics and laboratory data}

Baseline demographic and clinical characteristics of all study participants were collected. This included gender, age, height, body weight, and vascular risk factors such as hypertension (previous use of antihypertensive medication and systolic blood pressure $>140 \mathrm{mmHg}$ or diastolic blood pressure $>90 \mathrm{mmHg}$ at discharge), diabetes (previous use of a glucose-lowering medication and fasting blood glucose $>7 \mathrm{mmol} / \mathrm{L}$ or postprandial blood glucose after 2 hours $>11.1 \mathrm{mmol} / \mathrm{L}$ at discharge), hyper- lipidemia (previous use of a lipid-lowering medication and total cholesterol $>6.0 \mathrm{mmol} / \mathrm{L}$ or low-density lipoprotein cholesterol $>4.14 \mathrm{mmol} / \mathrm{L}$ at discharge), and current smoking. ${ }^{12-14}$ We also collated patient laboratory data, which included serum levels of glucose, hemoglobin A1c, total cholesterol, high-density lipoprotein cholesterol, triglycerides, low-density lipoprotein, albu$\mathrm{min}$, and calcium. Albumin-corrected calcium levels were calculated using the formula: albumin corrected calcium $(\mathrm{mg} / \mathrm{dL})=$ serum calcium $(\mathrm{mg} / \mathrm{dL})+0.8[4$-serum albumin $(\mathrm{g} / \mathrm{dL})] .{ }^{15}$

\section{Mortality information}

The vital status of the participants was ascertained using data obtained from Statistics Korea, a governmental statistical office that manages demographic statistics in Korea, which has been used and considered as reliable data in previous studies. ${ }^{16,17}$

\section{Statistical analysis}

Differences between the groups were analyzed using the $\chi^{2}$ test for categorical variables and the Student t-test or the MannWhitney $\mathrm{U}$ test for continuous variables. To test for significant associations between $\mathrm{mRS}$ distribution at discharge and serum levels of calcium or albumin-corrected calcium, ordinal logistic regression analyses was used, taking the 6 categorized $\mathrm{mRS}$ score (i.e., mRS scores 5 and 6 combined) as a dependent variable under the assumption of proportional odds. In addition, Cox proportional hazard models were constructed to test the effects of serum calcium or albumin-corrected calcium levels on mortality after stroke. For ordinal logistic regression models and Cox proportional hazard models, adjusted variables with $P$ values $<0.05$ were selected by univariate analysis. Serum calcium and albumin-corrected calcium levels were entered into multivariable models separately. To detect the threshold effect of calcium or albumin-corrected calcium levels on outcomes in model 1 , these two variables were classified by tertiles $(\mathrm{T} 1<8.9$; T2 8.9-9.2; T3 > 9.2 for calcium and T1 < 8.90; T2 8.90-9.28; T3 $>9.28$ for albumin-corrected calcium), and the tertiles were chosen based on sample size. Serum calcium and albumin-corrected calcium levels were analyzed as continuous data in model 2. Significance was set at a two-tailed $P$ level of $<0.05$. Values have been presented as frequencies (percentages), means \pm standard deviations, or medians [interquartile ranges (IQR)], as appropriate. All statistical analyses were performed using the SPSS 21.0 (IBM Inc., Armonk, NY, USA).

\section{Results}

Our acute stroke registry comprised 2,313 patients. However, we excluded patients with history of an intracranial hemorrhage 
$(\mathrm{n}=232)$, transient ischemic attack $(\mathrm{n}=124)$, and those without information on important clinical variables $(\mathrm{n}=15)$ or functional outcomes $(n=27)$. As a result, 1,915 stroke patients were enrolled in this study. Of these, 1,184 were men and 731 were women. Patients' age ranged from 16 to 98 years (mean $65.7 \pm 12.2$ years). The mean serum calcium and albumin-corrected calcium levels on admission were $8.97 \pm 0.58 \mathrm{mg} / \mathrm{dL}$ and $9.07 \pm 0.49 \mathrm{mg} /$ $\mathrm{dL}$ respectively, and the median initial NIHSS score was $4[2,7$ (IQR)]. The mean follow-up period was $917 \pm 609$ days (range $1-2,248$ days). The mortality rate was $1.6 \%$ (31 patients) at 1

Table 1. Patient baseline characteristics according to vital status

\begin{tabular}{|c|c|c|c|}
\hline & $\begin{array}{c}\text { All patients } \\
(\mathrm{n}=1,915)\end{array}$ & $\begin{array}{c}\text { Alive } \\
(\mathrm{n}=1,583)\end{array}$ & $\begin{array}{c}\text { Deceased } \\
(n=332)\end{array}$ \\
\hline \multicolumn{4}{|l|}{ Demographic variables } \\
\hline Male gender, $\mathrm{n}(\%)$ & $1,184(61.8)$ & $973(61.5)$ & $221(63.6)$ \\
\hline Age (years, mean $\pm S D$ ) & $65.7 \pm 12.2$ & $64.5 \pm 12.1$ & $71.6 \pm 10.9$ \\
\hline \multicolumn{4}{|l|}{ Cardiovascular risk factors } \\
\hline Hypertension, n (\%) & $1,292(67.5)$ & $1,067(67.4)$ & $225(67.8)$ \\
\hline Diabetes, $n(\%)$ & $650(33.9)$ & $530(33.5)$ & $120(36.1)$ \\
\hline Dyslipidemia, $n(\%)$ & $431(22.5)$ & $384(24.3)$ & $47(14.2)$ \\
\hline Habitual smoking, $n(\%)$ & $660(34.5)$ & $543(34.3)$ & $117(35.2)$ \\
\hline Body-mass index $\left(\mathrm{kg} / \mathrm{m}^{2}\right.$, mean $\left.\pm \mathrm{SD}\right)$ & $23.8 \pm 4.2$ & $24.1 \pm 3.0$ & $22.9 \pm 7.7$ \\
\hline \multicolumn{4}{|l|}{ Laboratory variables } \\
\hline $\begin{array}{l}\text { Systolic blood pressure, } \\
\text { mmHg (mean } \pm \text { SD) }\end{array}$ & $152.25 \pm 26.9$ & $152.6 \pm 27.0$ & $150.4 \pm 26.4$ \\
\hline $\begin{array}{l}\text { Diastolic blood pressure, } \mathrm{mmHg} \\
\text { (mean } \pm \mathrm{SD})\end{array}$ & $86.60 \pm 15.9$ & $86.9 \pm 15.9$ & $85.1 \pm 15.7$ \\
\hline Serum glucose, $\mathrm{mg} / \mathrm{dL}$, mean $\pm \mathrm{SD}$ & $115.29 \pm 41.5$ & $113.8 \pm 39.7$ & $122.2 \pm 49.0$ \\
\hline $\mathrm{Hb}$ A1c, \% (mean \pm SD) & $6.42 \pm 1.3$ & $6.4 \pm 1.3$ & $6.4 \pm 1.3$ \\
\hline Total cholesterol, $\mathrm{mg} / \mathrm{dL}$, mean $\pm \mathrm{SD}$ & $179.46 \pm 39.6$ & $181.1 \pm 39.7$ & $171.9 \pm 38.4$ \\
\hline $\begin{array}{l}\text { High-density lipoprotein, mg/dL } \\
\text { (mean } \pm \text { SD) }\end{array}$ & $44.11 \pm 12.4$ & $44.0 \pm 12.2$ & $44.4 \pm 13.4$ \\
\hline Triglycerides, mg/dL (mean \pm SD) & $127.62 \pm 75.7$ & $131.8 \pm 78.4$ & $107.8 \pm 57.0$ \\
\hline $\begin{array}{l}\text { Low-density lipoprotein, mg/dL } \\
(\text { mean } \pm S D)\end{array}$ & $109.82 \pm 33.4$ & $110.6 \pm 33.7$ & $106.1 \pm 31.8$ \\
\hline Albumin, g/dL (mean $\pm S D)$ & $3.89 \pm 0.4$ & $3.9 \pm 0.4$ & $3.6 \pm 0.5$ \\
\hline Calcium, mg/dL (mean \pm SD) & $8.97 \pm 0.6$ & $9.0 \pm 0.5$ & $8.8 \pm 0.7$ \\
\hline $\begin{array}{l}\text { Albumin-corrected calcium, mg/dL } \\
\text { (mean } \pm \text { SD) }\end{array}$ & $9.07 \pm 0.5$ & $9.07 \pm 0.4$ & $9.07 \pm 0.6$ \\
\hline \multicolumn{4}{|l|}{ Stroke characteristics } \\
\hline \multicolumn{4}{|l|}{ Stroke subtype, n (\%) } \\
\hline Large artery atherosclerosis & $558(29.1)$ & $470(29.7)$ & $88(26.5)$ \\
\hline Small vessel occlusion & $518(27.0)$ & $465(29.4)$ & $53(16.0)$ \\
\hline Cardioembolism & $375(19.6)$ & $281(17.8)$ & $94(28.3)$ \\
\hline Other determined etiology & $43(2.2)$ & $33(2.1)$ & $10(3.0)$ \\
\hline Undetermined etiology & $421(22.0)$ & $334(21.1)$ & $87(26.2)$ \\
\hline $\begin{array}{l}\text { NIHSS scores on admission, points } \\
\text { (IQR) }\end{array}$ & $4(2,7)$ & $3(1,6)$ & $6(3,14)$ \\
\hline \multicolumn{4}{|l|}{ Treatment received } \\
\hline Thrombolytic treatment, $\mathrm{n}(\%)$ & $90(4.7)$ & $74(4.7)$ & $16(4.8)$ \\
\hline Anticoagulation in acute period, $\mathrm{n}(\%)$ & $541(28.3)$ & $427(27.0)$ & $114(34.3)$ \\
\hline $\begin{array}{l}\text { Vascular intervention in acute period, } \\
\mathrm{n}(\%)\end{array}$ & $54(2.8)$ & $37(2.3)$ & $17(5.1)$ \\
\hline
\end{tabular}

SD, standard deviation; NIHSS, National Institutes of Health Stroke Scale; IOR, interquartile range. month post-admission, and the overall mortality rate was $17.3 \%$ (332 patients). Patient baseline characteristics by vital status are shown in Table 1.

Table 2 presents the results of multivariable ordinal logistic regression analyses of the effects of serum calcium and albumincorrected calcium levels on discharge mRS scores. Model 1 identified the second [adjusted odds ratio (OR) 1.32 (95\% confidence interval [CI] 1.07-1.61); $P<0.01]$ and third [OR 1.24 (95\% CI 1.01-1.53); $P=0.04]$ tertiles of the serum calcium level and the third [OR 1.24 (95\% CI 1.01-1.53); $P=0.04$ ] tertile of

Table 2. Multivariable ordinal logistic regression analyses of the relations between serum calcium and albumin-corrected calcium levels and discharge mRS scores

$\frac{\text { Serum calcium (mg/dL) }}{\text { Multivariable OR [Cl] Pfor trend }} \frac{\text { Albumin-corrected calcium (mg/dL) }}{\text { Multivariable OR [Cl] Pfor trend }}$

Model 1 *

Second vs. first $1.32[1.07-1.61] \quad<0.01 \quad 1.13[0.92-1.39] \quad 0.24$

Third vs. first $\quad 1.24[1.01-1.53] \quad 0.04 \quad 1.24[1.01-1.53] \quad 0.04$

$\begin{array}{lllll}\text { Model } 2^{\dagger} \quad 1.19[1.03-1.38] & 0.02 & 1.21[1.01-1.44] & 0.03\end{array}$

*Model 1: Serum calcium and albumin-corrected calcium levels as tertiles, adjusted for gender, age, hypertension, diabetes, habitual smoking, body-mass index, systolic blood pressure, serum glucose, albumin, triglycerides, stroke subtype, NIHSS scores on admission, and thrombolytic treatment $(P<0.05$ by univariate ordinal logistic regression analysis). ${ }^{\dagger}$ Model 2: Serum calcium and albumin-corrected calcium levels as continuous data (mg/dL), adjusted for gender, age, hypertension, diabetes, habitual smoking, body-mass index, systolic blood pressure, serum glucose, albumin, triglycerides, stroke subtype, NIHSS scores on admission, and thrombolytic treatment ( $P<0.05$ by univariate ordinal logistic regression analysis). mRS, modified Rankin Scale; OR, odds ratio; $\mathrm{Cl}$, confidence interval.

Table 3. Multivariable ordinal logistic regression analyses of the relations between clinical covariates and discharge mRS scores

\begin{tabular}{lcc}
\hline & Multivariable OR [Cl] & $P$ for trend \\
\hline Male gender & $0.91[0.74-1.11]$ & 0.34 \\
Age & $1.02[1.01-1.02]$ & $<0.001$ \\
Hypertension & $1.23[1.01-1.49]$ & 0.04 \\
Diabetes & $1.32[1.07-1.63]$ & 0.01 \\
Habitual smoking & $0.96[0.78-1.17]$ & 0.68 \\
Body-mass index & $0.97[0.95-0.99]$ & 0.01 \\
Systolic blood pressure, by 10 point increase & $1.02[0.99-1.06]$ & 0.22 \\
Serum glucose, by 10 point increase & $1.03[1.01-1.06]$ & 0.01 \\
Triglycerides, by 10 point increase & $0.99[0.98-1.00]$ & 0.19 \\
Albumin & $0.79[0.63-0.98]$ & 0.03 \\
Albumin-corrected calcium & $1.21[1.01-1.44]$ & 0.03 \\
Stroke subtype (vs. small vessel occlusion) & & \\
Large artery atherosclerosis & $0.97[0.77-1.22]$ & 0.79 \\
Cardioembolism & $0.69[0.52-0.90]$ & 0.01 \\
Other determined etiology & $1.75[0.96-3.18]$ & 0.07 \\
Undetermined etiology & $0.99[0.78-1.27]$ & 0.97 \\
NIHSS scores on admission & $1.44[1.41-1.48]$ & $<0.001$ \\
Thrombolytic treatment & $0.43[0.31-0.62]$ & $<0.001$ \\
\hline
\end{tabular}

$\mathrm{OR}$, odds ratio; $\mathrm{Cl}$, confidence interval; NIHSS, National Institutes of Health Stroke Scale. 
the albumin-corrected calcium level as independent risk factors for a poor discharge outcome. Among the confounders, variables with $P$ values $<0.05$ in univariate analyses were selected for adjustment in the analysis. A significant relationship was also observed in model 2 using serum calcium [OR 1.19 (95\% CI 1.03-1.38); $P=0.02]$ and albumin-corrected calcium levels [OR 1.21 (95\% CI 1.01-1.44); $P=0.03$ ] as linear variables. Details of multivariable ordinal logistic regression analysis results are summarized in Table 3. In terms of mortality, multivariable analysis was performed using Cox proportional hazard regression analysis models (Table 4). Model 1 identified the third tertile [adjusted hazard ratio (HR) 1.40 (95\% CI 1.07-1.83); $P=0.02$ ] of albumin-corrected calcium level as an independent risk factor for long-term mortality. The relationship between albumin-corrected calcium level and mortality was also found to be significant when albumin-corrected calcium level was analyzed as a linear variable [mg/dL; HR 1.46 (95\% CI 1.16-1.84); $P<0.001$, model 2]. In addition, male gender, age, serum glucose level, serum triglyceride level, serum albumin level, stroke subtype, and NIHSS scores on admission were found to be significantly associated with long-term mortality by multivariable analysis (Table 5). However, no significant association was found between serum calcium level and long-term mortality.

\section{Discussion}

The present study shows that high levels of albumin-corrected calcium are associated with a poor discharge outcome and a higher incidence of mortality after acute ischemic stroke. This association was found using the highest tertile model and the continuous $1 \mathrm{mg} / \mathrm{dL}$ increase model. Furthermore, the association between the discharge outcome and serum calcium level was also found to be significant when we used serum calcium

Table 4. Multivariable Cox regression analyses of the relations between serum calcium and albumin-corrected calcium levels and all-cause death

\begin{tabular}{|c|c|c|c|c|}
\hline & \multicolumn{2}{|c|}{ Serum calcium (mg/dL) } & \multicolumn{2}{|c|}{ Albumin-corrected calcium $/ \mathrm{mg} / \mathrm{dL}$. } \\
\hline & Multivariable HR [CI] & $P$ value & Multivariable HR [Cl] & $P$ value \\
\hline \multicolumn{5}{|l|}{ Model ${ }^{*}$} \\
\hline Second vs. first & $0.93[0.71-1.21]$ & 0.58 & 0.99 [0.76-1.30] & 0.95 \\
\hline Third vs. first & $1.06[0.80-1.41]$ & 0.69 & $1.40[1.07-1.83]$ & 0.02 \\
\hline Model $2^{\dagger}$ & 1.09 [0.90-1.32] & 0.37 & $1.46[1.16-1.84]$ & $<0.001$ \\
\hline
\end{tabular}

*Model 1: Serum calcium and albumin-corrected calcium levels as tertiles, adjusted for gender, age, hyperlipidemia, body-mass index, diastolic blood pressure, serum glucose, albumin, triglycerides, stroke subtype, and NIHSS scores on admission $\left(P<0.05\right.$ by univariate $C o x$ regression analysis). ${ }^{\dagger}$ Model 2 : Serum calcium and albumin-corrected calcium level as continuous data (mg/dL), adjusted for gender, age, hyperlipidemia, body-mass index, diastolic blood pressure, serum glucose, albumin, triglyceride, stroke subtype, and NIHSS scores on admission $(P<0.05$ by univariate Cox regression analysis).

$\mathrm{HR}$, hazard ratio; $\mathrm{Cl}$, confidence interval. levels in a continuous $1 \mathrm{mg} / \mathrm{dL}$ increase model. However, in the tertile model, the middle tertile was found to be more strongly associated with a poor outcome than the highest tertile. With regard to mortality, serum calcium and albumin-corrected calcium showed discrepant results as the association between mortality and albumin-corrected calcium level was identified by the highest tertile model and the continuous $1 \mathrm{mg} / \mathrm{dL}$ increase model, but these relations were not found for serum calcium.

The differences in the results obtained for the serum calcium and albumin-corrected calcium levels may be explained by the physiologic characteristics of $\mathrm{Ca}^{2+}$. About half of the calcium in the serum is bound to serum proteins, particularly to albumin. Accordingly, changes in protein concentration alone cause changes in total calcium without affecting the physiologically and clinically important ionized calcium, and thus, adjustment of the total serum calcium concentration for albumin is essential when attempting to detect abnormal values. ${ }^{18}$ For these reasons, albumincorrected calcium is a better parameter for evaluating the effect of calcium at the cellular level when directly measured ionized calcium concentration is not available.

The underlying biological mechanism responsible for the poor short-term outcome and increased mortality associated with elevated albumin-corrected calcium levels has not been established. Experimental studies have demonstrated that influx of $\mathrm{Ca}^{2+}$ into neuronal cells is a mechanism of ischemic cell death. Glutamatestimulated $\mathrm{Ca}^{2+}$ influx into cultured neurons by ${ }^{45} \mathrm{Ca}^{2+}$, and elevated $\mathrm{Ca}^{2+}$ levels after NMDA receptor stimulation has been observed repeatedly using fluorescent probes. ${ }^{19,20}$ Furthermore, it has also been shown that inhibition of the effectors of $\mathrm{Ca}^{2+}$ tox-

Table 5. Multivariable Cox regression analyses of the relations between clinical covariates and all-cause death

\begin{tabular}{lcc}
\hline & Multivariable HR [Cl] & $P$ value \\
\hline Male gender & $1.37[1.09-1.73]$ & 0.01 \\
Age & $1.04[1.03-0.05]$ & 0.01 \\
Hyperlipidemia & $1.28[0.93-1.76]$ & 0.13 \\
Body-mass index & $0.97[0.94-1.01]$ & 0.15 \\
Diastolic blood pressure & $0.96[0.89-1.03]$ & 0.26 \\
$\quad$ per 10 mmHg increase) & $1.03[1.01-1.05]$ & 0.04 \\
Serum glucose (per 10 mg/dL increase) & $0.98[0.96-0.99]$ & 0.03 \\
Triglycerides (per 10 mg/dL increase) & $0.41[0.32-0.53]$ & $<0.001$ \\
Albumin & $1.46[1.16-1.84]$ & $<0.001$ \\
Albumin-corrected calcium & & \\
Stroke subtype (vs. small vessel occlusion) & $1.25[0.88-1.77]$ & 0.21 \\
$\quad$ Large artery atherosclerosis & $1.59[1.11-2.28]$ & 0.01 \\
Cardioembolism & $4.85[2.4-9.79]$ & $<0.001$ \\
Other determined etiology & $1.55[1.08-2.22]$ & 0.02 \\
$\quad$ Undetermined etiology & $1.06[1.05-1.08]$ & 0.01 \\
NIHSS scores on admission &
\end{tabular}

HR, hazard ratio; $\mathrm{Cl}$, confidence interval; NIHSS, National Institutes of Health Stroke Scale. 
icity, such as calmodulin, ${ }^{21}$ calcineurin, ${ }^{22}$ or neuronal nitric oxide synthase, ${ }^{23}$ protects neurons against the toxic effects of excitatory amino acids. These studies suggest that elevated extracellular $\mathrm{Ca}^{2+}$ levels increase the risk of early neuronal death caused by NMDA receptor-mediated $\mathrm{Ca}^{2+}$ intracellular influx.

Mitochondrial dysfunction also contributes to delayed neuronal death, and it was established decades ago that massive calcium accumulation triggers mitochondrial damage. ${ }^{24}$ Increases in mitochondrial permeability are caused by the formation of high conductivity proteinaceous pores that allow the passage of ions and molecules. ${ }^{25,26}$ Furthermore, mitochondria exposed to calcium swell and release their contents. ${ }^{25}$ In addition, oxidative stress and mitochondrial calcium accumulation activate mitochondrial permeability transition and lead to depolarization-coupled production of reactive oxygen species. ${ }^{27}$ This relationship between calcium and mitochondria may explain the association of the calcium level with a poor neurological outcome in stroke.

The results of the present study should be interpreted with some caution. First, our study was conducted in a retrospective manner, and patients without calcium level, height, or admission NIHSS data were excluded from the analysis. However, only $2.12 \%$ of all potential participants were excluded, and thus, we believe that the quality of the data was acceptable. Second, we used discharge mRS scores as a measure of short-term neurological outcome, and thus, these scores were allocated at different times after stroke onset; the 3-month follow-up NIHSS and mRS scores were not collected. However, $\mathrm{mRS}$ was administered when medically and neurologically stabilized patients were transferred to rehabilitation services or discharged to home, and mRS scores at discharge may better represent the severity of early neurologic involvement compared to the 3-month follow-up scores because of individual differences in medical care. Third, none of the patients in our study had hypercalcemia (calcium level $\geq 12.0 \mathrm{mg} / \mathrm{dL}$ ). Due to the retrospective nature of our study, we were unable to correct this issue. Fourth, information regarding stroke location, lesion volume, and post-discharge medical care quality, the well-known factors associated with short and long-term clinical outcomes of ischemic stroke patients, was not captured in this study. Fifth, serum albumin level could be an important interacting variable for the relationship between albumin-corrected calcium level and stroke outcome. A thorough statistical analysis for such a relation was not performed in the current study. However, albumin-corrected calcium level was a significant prognostic factor for short- and long-term stroke outcomes, after adjusting for serum albumin level. Finally, the calcium level was checked once on the day of admission, whereas Ovbiagele et al. reported that serum calcium levels obtained within 72-96 hours of stroke onset are of prognostic significance. ${ }^{28}$ However, the annual intra-individual calcium level variation is only $2 \%$, and calcium transport from the extracellular area into neuronal cells would not be sufficient to change serum levels to the degree noted in our study. ${ }^{29}$ Thus, we argue that the timing of the calcium level measurements is not important in the context of this study.

\section{Conclusion}

We found that higher albumin-corrected calcium levels were of prognostic significance in terms of early neurologic outcome and long-term mortality after acute ischemic stroke. Furthermore, albumin-corrected calcium showed a more clear association in our results than serum calcium. Prospective studies with direct measurements of calcium ion concentrations at various times after stroke onset are required to obtain more information regarding the pathophysiologic role of $\mathrm{Ca}^{2+}$ in ischemic neuronal injury.

\section{References}

1. Kristian T, Siesjo BK. Calcium in ischemic cell death. Stroke 1998;29:705-718.

2. Nicholson C, Bruggencate GT, Steinberg R, Stockle H. Calcium modulation in brain extracellular microenvironment demonstrated with ion-selective micropipette. Proc Natl Acad Sci US A 1977;74:1287-1290.

3. Tymianski $\mathrm{M}$, Tator $\mathrm{CH}$. Normal and abnormal calcium homeostasis in neurons: a basis for the pathophysiology of traumatic and ischemic central nervous system injury. Neurosurgery 1996;38:1176-1195.

4. Gelmers HJ, Gorter K, de Weerdt CJ, Wiezer HJ. A controlled trial of nimodipine in acute ischemic stroke. N Engl J Med 1988; 318:203-207.

5. Mohr JP, Orgogozo JM, Harrison MJG, Hennerici M, Wahlgren NG, Gelmers JH, et al. Meta-analysis of oral nimodipine trials in acute ischemic stroke. Cerebrovasc Dis 1994;4:194-196.

6. Walker GL, Williamson PM, Ravich RB, Roche J. Hypercalcaemia associated with cerebral vasospasm causing infarction. J Neurol Neurosurg Psychiatry 1980;43:464-467.

7. Bogousslavsky J, Caplan LR. Uncommon causes of stroke. 1st ed. Cambridge, UK; New York, NY, USA: Cambridge University Press, 2001.

8. Ovbiagele B, Liebeskind DS, Starkman S, Sanossian N, Kim D, Razinia T, et al. Are elevated admission calcium levels associated with better outcomes after ischemic stroke? Neurology 2006; 67:170-173.

9. Buck BH, Liebeskind DS, Saver JL, Bang OY, Starkman S, Ali LK, et al. Association of higher serum calcium levels with smaller infarct volumes in acute ischemic stroke. Arch Neurol 2007; 
64:1287-1291.

10. Appel SA, Molshatzki N, Schwammenthal Y, Merzeliak O, Toashi M, Sela BA, et al. Serum calcium levels and long-term mortality in patients with acute stroke. Cerebrovasc Dis 2011; 31:93-99.

11. Adams HP Jr, Bendixen BH, Kappelle LJ, Biller J, Love BB, Gordon DL, et al. Classification of subtype of acute ischemic stroke. Definitions for use in a multicenter clinical trial. TOAST. Trial of Org 10172 in Acute Stroke Treatment. Stroke 1993;24: 35-41.

12. Chobanian AV, Bakris GL, Black HR, Cushman WC, Green LA, Izzo JL Jr, et al. Seventh report of the Joint National Committee on Prevention, Detection, Evaluation, and Treatment of High Blood Pressure. Hypertension 2003;42:1206-1252.

13. Kim BJ, Lee SH, Ryu WS, Kang BS, Kim CK, Yoon BW. Low level of low-density lipoprotein cholesterol increases hemorrhagic transformation in large artery atherothrombosis but not in cardioembolism. Stroke 2009;40:1627-1632.

14. Alberti KG, Zimmet PZ. Definition, diagnosis and classification of diabetes mellitus and its complications. Part 1: diagnosis and classification of diabetes mellitus provisional report of a WHO consultation. Diabet Med 1998;15:539-553.

15. Bushinsky DA, Monk RD. Electrolyte quintet: Calcium. Lancet 1998;352:306-311.

16. Jee SH, Sull JW, Park J, Lee SY, Ohrr H, Guallar E, et al. Bodymass index and mortality in Korean men and women. N Engl J Med 2006;355:779-787.

17. Ryu WS, Lee SH, Kim CK, Kim BJ, Yoon BW. Effects of low serum triglyceride on stroke mortality: a prospective follow-up study. Atherosclerosis 2010;212:299-304.

18. Payne RB, Carver ME, Morgan DB. Interpretation of serum total calcium: effects of adjustment for albumin concentration on frequency of abnormal values and on detection of change in the individual. J Clin Pathol 1979;32:56-60.
19. Michaels RL, Rothman SM. Glutamate neurotoxicity in vitro: antagonist pharmacology and intracellular calcium concentrations. J Neurosci 1990;10:283-292.

20. Milani D, Guidolin D, Facci L, Pozzan T, Buso M, Leon A, et al. Excitatory amino acid-induced alterations of cytoplasmic free $\mathrm{Ca}^{2+}$ in individual cerebellar granule neurons: role in neurotoxicity. J Neurosci Res 1991;28:434-441.

21. Marcaida G, Minana MD, Grisolia S, Felipo V. Lack of correlation between glutamate-induced depletion of ATP and neuronal death in primary cultures of cerebellum. Brain Res 1995; 695:146-150.

22. Marcaida G, Kosenko E, Minana MD, Grisolia S, Felipo V. Glutamate induces a calcineurin-mediated dephosphorylation of $\mathrm{Na}+, \mathrm{K}(+)$-ATPase that results in its activation in cerebellar neurons in culture. J Neurochem 1996;66:99-104.

23. Dawson VL, Dawson TM, Bartley DA, Uhl GR, Snyder SH. Mechanisms of nitric oxide-mediated neurotoxicity in primary brain cultures. J Neurosci 1993;13:2651-2661.

24. Nicholls DG. A role for the mitochondrion in the protection of cells against calcium overload? Prog Brain Res 1985;63:97-106.

25. Gunter TE, Pfeiffer DR. Mechanisms by which mitochondria transport calcium. Am J Physiol 1990;258:C755-786.

26. Gunter TE, Gunter KK, Sheu SS, Gavin CE. Mitochondrial calcium transport: physiological and pathological relevance. Am J Physiol 1994;267:C313-339.

27. Zoratti M, Szabo I. The mitochondrial permeability transition. Biochim Biophys Acta 1995;1241:139-176.

28. Ovbiagele B, Starkman S, Teal P, Lyden P, Kaste M, Davis SM, et al. Serum calcium as prognosticator in ischemic stroke. Stroke 2008;39:2231-2236.

29. Valero-Politi J, Ginard-Salva M, Gonzalez-Alba JM. Annual rhythmic and non-rhythmic biological variation of magnesium and ionized calcium concentrations. Clin Chem Lab Med 2001;39:45-49. 